Edunomika - Vol. 03, No. 01 (Februari 2019)

\title{
PENGARUH MANAJEMEN MUTU DAN KUALITAS PELAYANAN TERHADAP KEPUASAN PASIEN RAWAT INAP DI RSUD KABUPATEN KARANGANYAR
}

\author{
Eko Sutopo, Sudarwati, Istiqomah \\ Prodi Manajemen Fakultas Ekonomi UNIBA Surakarta \\ pakdeeko81@gmail.com
}

\begin{abstract}
The purpose of this study was to find out: the effect of service quality, reliability, responsiveness, and empathy both jointly and partially on the satisfaction of inpatients in the Karanganyar District Hospital. Judging from the type or type, this research is explanatory research (explanation). The population in this study were 1006 patients hospitalized in Karanganyar Hospital. As a sample 100 people were taken using proportional random sampling technique. The data collection technique used is by questionnaire method, documentation and literature study. The data analysis technique in this study is the classic assumption test, multiple linear regression analysis, $t$ test, $F$ test and coefficient of determination. Based on the results of the tests that have been carried out it can be concluded as follows: (1) There is a positive and significant effect simultaneously management of quality, reliability, responsiveness, and empathy on the satisfaction of inpatients in Karanganyar District Hospital. (2) There is a positive and significant effect of partial quality management on the satisfaction of inpatients in the RSUD. (3) There is a positive and significant partial effect of reliability on the satisfaction of inpatients in the RSUD. (4) There is a positive and significant influence partially on responsiveness to the satisfaction of inpatients in the RSUD. (5) There is a positive and significant partial effect of empathy on the satisfaction of inpatients in the RSUD.
\end{abstract}

Keywords: quality management, reliability, responsiveness, empathy, patient satisfaction

\section{PENDAHULUAN}

Rumah sakit dalam sistem kesehatan nasional merupakan bagian dari sub sistem pelayanan kesehatan nasional yang tujuan utamanya adalah meningkatkan derajat kesehatan masyarakat. Dalam Undang-Undang No. 44 Tahun 2009 dinyatakan bahwa rumah sakit adalah institusi yang menyelenggarakan layanan kesehatan perorangan secara paripurna dalam bentuk layanan rawat inap, rawat jalan, dan gawat darurat. Pelayanan kesehatan secara paripurna tersebut adalah pelayanan kesehatan yang meliputi promotif, preventif, kuratif, dan rehabilitatif (Undang-Undang No. 44 Tahun, 2009).

Saat ini rumah sakit telah berkembang menjadi institusi yang bersifat sosio-ekonomis, yaitu institusi yang bersifat sosial tetapi mendatangkan keuntungan dan dijalankan berdasarkan prinsipprinsip ekonomi. Sebagai organisasi sosio-ekonomis tersebut, rumah sakit dituntut untuk dapat menjalankan dan mempertahankan kelangsungan organisasinya secara mandiri, rumah sakit harus 
dikelola secara efisien dan profesional agar menghasilkan jasa pelayanan yang dapat meningkatkan derajat kesehatan masyarakat (Adisasmito, 2008).

Era globalisasi menyebabkan persaingan antar rumah sakit, baik rumah sakit pemerintah, rumah sakit swasta, maupun rumah sakit asing. Munculnya persaingan ini menyebabkan perubahan perilaku konsumen rumah sakit. Banyaknya pilihan rumah sakit menyebabkan konsumen semakin cerdas dalam menentukan pilihan, dan akhirnya konsumen mempunyai tuntutan yang tinggi mengenai kualitas pelayanan (Adisasmito, 2008). Berdasarkan studi terdahulu, memperoleh konsumen baru membutuhkan biaya lima kali lipat dari biaya untuk mempertahankan konsumen yang sudah ada saat ini (Lupiyoadi dan Hamdani, 2011).

Jumlah kunjungan keseluruhan dan jumlah kunjungan pasien lama membutuhkan suatu analisis untuk mengetahui perilaku pasien dalam menentukan keputusannya. Hal tersebut karena upaya mempertahankan pasien lama merupakan aset yang sangat berharga bagi rumah sakit. Guna mempertahankan keberadaan pasien, rumah sakit membutuhkan peran perawat sebagai tenaga medis yang berhubungan langsung dengan pasien. Oleh karena itu, manajemen rumah sakit perlu mengidentifikasi faktor-faktor apa saja yang berhubungan dengan kepuasan pasien rawat inap sehingga mendorong peningkatan kinerjanya dalam bentuk pelayanan yang berkualitas. Parasuraman dalam Sabihaini (2010: 38) menyatakan bahwa dimensi pelayanan dapat diukur dengan instrumen yang disebut SERVQUAL INSTRUMENT yang terdiri atas lima dimensi yaitu: dimensi Tangible, Reliability, Responsiveness, Assurance, dan Empathy.

Tangible, yaitu berbagai fasilitas yang dapat dilihat dan digunakan organisasi dalam upaya memenuhi kepuasan konsumen. Reliability merupakan kehandalan petugas dalam memberikan pelayanan sesuai yang dijanjikan. Responsiveness merupakan sikap tanggap, mau mendengarkan dan merespon dalam upaya memuaskan pasien rawat inap. Assurance merupakan rasa aman atau kenyamanan yang dirasakan atau diterimapasien rawat inap. Empathy adalah kemampuan pegawai dalam memberikan perhatian yang bersifat pribadi kepada pasien rawat inap.

Dengan demikian, pengalaman pasien rawat inap terhadap pelayanan yang diberikan, komunikasi pemasaran yang dilakukan oleh rumah sakit, dan kekuatan hambatan pindah diharapkan dapat menjadi faktor-faktor yang berhubungan dengan kepuasan pasien rawat inap, sehingga apabila pasien merasa puas maka secara tidak langsung dapat membantu akan rumah sakit dapat mempertahankan konsumen lama dan lebih lanjut meraih konsumen baru. Dalam suatu proses keputusan pembelian, konsumen tidak akan berhenti hanya sampai proses pembelian, tetapi konsumen akan melakukan penilaian pascapembelian (Schiffman dan Kanuk, 2008).

Penilaian pascapembelian tersebut memberikan umpan balik seperti pengalaman terhadap psikologis konsumen yang akan membantu mempengaruhi keputusan yang berkaitan diwaktu yang akan datang (Schiffman dan Leslie, 2008). Selain itu, keputusan pembelian kembali juga dipengaruhi oleh program promosi atau komunikasi pemasaran yang dilakukan oleh penyedia jasa (Setiawan, 2011).

Sesuai dengan visi RSUD Kabupaten Karanganyar untuk menjadi rumah sakit bertaraf Nasional yang memberikan manfaat nyata bagi masyarakat dengan menyediakan pelayanan komprehensif bermutu tinggi, pelayanan manajemen rumah sakithadir selama 24 jam untuk melayani kebutuhan perlengkapan di bangsal. Semua fasilitas yang tersedia di bangsal perawatan RSUD Karanganyar dikelola dan disediakan secara khusus sesuai dengan fungsinya untuk memenuhi kebutuhan akan pelayanan pasien di bangsal.

Pelayanan manajemen rumah sakit RSUD Kabupaten Karanganyar kepada tiap bagian di rumah sakit khususnya bangsal pasien rawat inap termasuk bagian dari upaya Pemerintah dalam 
menegakkan citra lembaga Pemerintah sebagai abdi masyarakat. Pelayanan yang diselenggarakan RSUD ini secara empirik telah memberikan hasil berupa peningkatan produktivitas pelayanan minimal secara kuantitatif yakni makin meningkatnya pasien dari tahun ke tahun. Seiring dengan makin meningkatnya kebutuhan masyarakat akan pelayanan kesehatan, RSUD Kabupaten Karanganyar sebagai organisasi pelaksana pelayanan di wilayah kerjanya harus meningkatkan kualitas pelayanan kepada masyarakat, karena pada hakikatnya kualitas ditentukan hanya oleh masyarakat. Salah satu cara untuk meningkatkan kualitas pelayanan adalah dengan memenuhi harapan masyarakat dengan cara meningkatkan mutu pelayanan. Rasa puas orang yang memerlukan kualitas pelayanan bisa diartikan dengan membandingkan bagaimana pandangan antara pelayanan yang diterima dengan harapan pelayanan yang diharapkan. Sementara itu harapan masyarakat dapat terbentuk berdasarkan pengalaman maupun informasi. Ini diperkuat oleh temuan Ma'ruf (2016) bahwa terdapat pengaruh yang signifikan antara pelayanan yang meliputi layanan dokter/perawat, layanan fasilitas, layanan administrasi dan keuangan dengan kepuasan pasien.

Kenyataan tersebut tidak saja disebabkan oleh berbagai hambatan, melainkan masih ada hal lain yang menjadi penyebabnya, seperti dalam memberikan pelayanan publik tidak diikuti oleh peningkatan kualitas birokrasi yang memberikan pelayanan kepada masyarakat. Sering terdapat keluhan dari masyarakat selama ini karena adanya persepsi atau anggapan sementara yang keliru terhadap proses pelayanan di RSUD Kabupaten Karanganyar yaitu proses pelayanan lama dan berbelit-belit. Untuk menghindari kesan yang negatif tersebut, maka mau tidak mau manajemen RSUD Kabupaten Karanganyar sebagai bagian integral pelayanan rumah sakiit harus dapat bekerja secara profesional, dalam pengertian bahwa meskipun terjadi penambahan rantai birokrasi, namun proses penyelesaian jasa pelayanan dapat dilakukan secara lebih cepat dengan kualitas yang lebih baik pula.

\section{TINJAUAN PUSTAKA}

\section{Kepuasan Pasien}

Menurut Kotler dan Andreasen (2011) kepuasan adalah satu bentuk perasaan seseorang yang mendapatkan pengalaman kinerja (hasil) yang telah memenuhi harapannya. Maka kepuasan adalah suatu fungsi yang bertingkat secara relatif dari suatu harapan dan atau penampakan hasil yang diterima. Seseorang akan memiliki pengalaman dalam satu atau tiga jenis kepuasan. Jika hasil yang diperolehnya melebihi dari yang diharapkannya, maka orang tersebut akan mendapatkan kepuasan pada tingkat tinggi, jika hasil yang diterimanya sesuai dengan yang ia harapkan, maka orang tersebut akan puas sedangkan jika hasil yang diterimanya kurang dari yang diharapkan, maka orang tersebut akan merasa kecewa.

Menurut Engel seperti dikutip Basu Swastha (2011:233) kepuasan dipengaruhi oleh faktor dalam dan luar. Faktor dalam antara lain : sumber daya, pendidikan, pengetahuan, sikap, gaya hidup dan demografi. Sedang faktor dari luar antara lain budaya, sosial ekonomi, pengaruh keluarga dan situasi.Menurut Dharmmesta dan Handoko (2007:44) kepuasan konsumen merupakan reaksi perilaku sesudah pembelian terhadap apa yang sudah terlanjur dibeli. Kepuasan konsumen juga mempengaruhi pengambilan keputusan pembelian ulang terhadap pembelian jasa yang sama dan akan mempengaruhi ucapan konsumen pada pihak lain/luar tentang produksi yang dihasilkan 


\section{Manajemen Mutu}

Hansen dan Mowen (2009:17) mengemukakan bahwa TQM adalah suatu perbaikan berkelanjutan yang mana hal ini adalah sesuatu yang mendasar sifatnya bagi pengembangan proses manufaktur yang sempurna. Memproduksi produk dan pengurangan pemborosan yang sesuai dengan standar merupakan dua tujuan umum perusahaan. Filosofi dari manajemen mutu sebenarnya yaitu dimana sebuah perusahaan berusaha menciptakan suatu lingkungan yang memungkinkan pekerjanya menghasilkan produk atau jasa yang sempurna (zero-defect), dan mencoba memperbaiki kesalahan dimasa lalu. Penekanan pada kualitas juga telah menciptakan kebutuhan akan adanya suatu system akuntansi manajemen yang menyediakan informasi keuangan dan nonkeuangan tentang kualitas.

Manajemen mutu juga diterjemahkan sebagai pendekatan berorientasi pelanggan yang memperkenalkan perubahan manajemen yang sistematik dan perbaikan terus menerus terhadap proses, produk, dan pelayanan suatu organisasi. Proses manajemen mutu memiliki input yang spesifik (keinginan, kebutuhan, dan harapan pelanggan), mentransformasi (memproses) input dalam organisasi untuk memproduksi barang atau jasa yang pada gilirannya memberikan kepuasan kepada pelanggan (output). Tujuan utama total quality management adalah perbaikan mutu pelayanan secara terus-menerus (Natha, 2008:4).

Berdasarkan beberapa definisi diatas, maka dapat disimpulkan bahwa manajemen mutu merupakan sebuah pendekatan yang menekankan peningkatan proses produksi secara terus menerus melalui eliminasi pemborosan, peningkatan kualitas, serta mengurangi biaya produksi. Dengan demikian, tujuan akhir dari konsep manajemen mutu adalah untuk mencapai kepuasan pelanggan dan upaya mengurangi suatu kesalahan/ketidaksempurnaan barang atau jasa yang dihasilkan.

\section{Kehandalan (reliability)}

Menurut Lupiyoadi (2001:148), kehandalan adalah kemampuan perusahaan untuk memberikan pelayanan sesuai yang dijanjikan secara akurat dan terpercaya. Kinerja harus sesuai dengan harapan pelanggan yang berarti ketepatan waktu, pelayanan yang sama, untuk semua pelanggan tanpa kesalahan, sikap yang simpatik, dan dengan akurasi yang tinggi.Tjiptono (2006:69( mendefinsikan kehandalan mencakup dua hal pokok, yaitu konsistensi kerja (perpomance) dan kemampuan untuk dipercaya (dependability). Hal ini berarti perusahaan memberikan jasanya secara tepat semenjak perusahaan yang bersangkutan memenuhi janjinya, misalnya menyampaikan jasanya sesuai dengan jadwal yang disepakati.

Secara singkat definisi kehandalan menurut Tjiptono (2007:14) adalah kemampuan memberikan pleyanan yang dijanjikan dengan segara, akurat dan memuaskan. Menurut Zahruli (2006) kehandalan yaitu kemampuan memberikan pelayanan yang sesuai secara akurat dan terpercaya, sikap simpatik dan dengan akurasi yang tinggi kepada para pasien. Keandalan diukur dengan tindakan pelayanan yang akurat oleh tenaga medis, profesionalisme dalam menangani keluhan pasien oleh para tenaga medis, melayani dengan baik dan ramah saat melakukan pengobatan dan perawatan, memberikan pelayanan dengan tepat dan benar sesuai dengan prosedur yang ditetapkan dalam memberikan pelayanan selalu sesuai dengan jadwal yang telah ditetapkan.

\section{Daya Tanggap (responsiveness)}

Menurut Lupiyoadi (2001:148) daya tanggap adalah suatu kemauan untuk membantu dan memberikan pelayanan yang cepat (responsif) dan tepat kepada pelanggan, dengan penyampaian informasi yang jelas. Membiarkan konsumen menunggu tanpa adanya suatu alasan yang jelas 
menyebabkan persepsi yang negatif dalam kualitas pelayanan".sedangkan menurut Fandy Tjiptono (1996:70) daya tanggap adalah "keinginan para staf untuk membantu para pelanggan dan memberikan pelayanan dengan tangga".

\section{Empati (empathy)}

Lupiyoadi (2001:148) menerangkan empati adalah memberikan perhatian yang tulus dan bersifat individual atau pribadi yang diberikan kepada para pelanggan dengan berupaya memahami keinginan konsumen.Dimana suatu perusahaan diharapkan memiliki pengertian dan pengetahuan tentang pelanggan, memahami kebutuhan pelanggan secara spesifik, serta memiliki waktu pengoperasian yang nyaman bagi pelanggan. Menurut Tjiptono (2006:70), empati adalah kemudahan dalam melakukan hubungan, komunikasi yang baik, perhatian pribadi, dan memahami kebutuhan pelanggan.Kotler (2007:53) mendefinisikan empati sebagai tingkat perhatian pribadi terhadap para pelanggan.

\section{METODE PENELITIAN}

Penelitian ini menggunakan tipe penelitian deskriptif dengan pendekatan kuantitatif.Penelitian dilaksanakan di RSUD Kabupaten Karanganyar.Populasi dalam penelitian ini adalah semua pasien rawat inap di RSUD Kabupaten Karanganyar bulan Oktober 2018 sebanyak 1.006 orang. Sampel dalam penelitian ini sebanyak $10 \%$ dari populasi atau 100orang. Metode pengambilan sampel yang dalam penelitian ini adalah incidental random sampling.

Teknik pengumpulan data yang digunakan dalam penelitian ini adalah :observasi, dokumentasi, kuesioner dan studi kepustakaan. Jenis data yang diperlukan yaitu : data primer yang diperoleh secara langsung dari responden melalui kuesioner (angket); sedangkandata sekunder berupa deskripsi RSUD Kabupaten Karanganyar.

Teknik analisis yang digunakan adalah : (1) uji asumsi klasik: uji normalitas, uji multikolinearitas, uji heteroskedastisitas dan uji autokorelasi;(2) analisis regresi linear berganda, (3) uji F, (4) uji t dan (5) analisis koefisien determinasi $\left(\mathrm{R}^{2}\right)$.

\section{PEMBAHASAN}

\section{Analisis Regresi Linear Berganda}

Persamaan regresi linear berganda yang diperoleh yaitu :

$Y=-5,604+0,638 X_{1}+0,145 X_{2}+0,309 X_{3}+0,266 X_{4}+e$

Interpretasi :

a. $\quad$ Konstanta $(a)=-5,604$

Artinya apabila faktor manajemen mutu, reliability, responsiveness, empathy atau variabel bebas sebesar 0, maka kepuasan pasien rawat inap di RSUD Kabupaten Karanganyar akan menurun sebesar 5,604.

b. Koefisien regresi variabel manajemen mutu $\left(b_{1}\right)=0,638$

Artinya variabel manajemen mutu berpengaruh positif terhadap kepuasan pasien rawat inap di RSUD Kabupaten Karanganyar dengan asumsi reliability, responsiveness, dan empathy dalam keadaan tetap.

c. Koefisien regresi variabel reliability $\left(\mathrm{b}_{2}\right)=0,145$ 
Artinya variable reliability pegawai berpengaruh positif terhadap kepuasan pasien rawat inap di RSUD Kabupaten Karanganyar dengan asumsi manajemen mutu, responsiveness, dan empathy dalam keadaan tetap.

d. Koefisien regresi variabel responsiveness $\left(b_{3}\right)=0,309$

Artinya variabel responsiveness berpengaruh positif terhadap kepuasan pasien rawat inap di RSUD Kabupaten Karanganyar dengan asumsi manajemen mutu, reliability, dan empathy dalam keadaan tetap.

e. Koefisien regresi variabel empathy $\left(\mathrm{b}_{4}\right)=0,266$

Artinya variabel empathy berpengaruh positif terhadap kepuasan pasien rawat inap di RSUD Kabupaten Karanganyar dengan asumsi manajemen mutu, reliability, dan responsiveness dalam keadaan tetap.

\section{Uji F}

Hasil uji secara serempak (Uji F) diketahui besarnya nilai $\mathrm{F}$ hitung $=102,487$ lebih besar dari F tabel $(2,49)$, sehingga dapat disimpulkan secara bersama-sama variabel bebas mempengaruhi kepuasan pasien. Dengan demikian hipotesis penelitian yang menyatakan : "Diduga ada pengaruh positif manajemen mutu, reliability, responsiveness, dan empathy secara bersama-sama terhadap kepuasan pasien rawat inap di RSUD Kabupaten Karanganyar" dapat dibuktikan. Dengan demikian maka variabel manajemen mutu, reliability, responsiveness dan empathy secara bersama-sama berpengaruh signifikan terhadap kepuasan pasien.

\section{Uji t}

a. Uji t pengaruh manajemen mutu terhadap kepuasan pasien

Hasil uji diperoleh nilai t hitung $(9,333)$ lebih besar dari t tabel $(1,960)$, maka Ho ditolak yang artinya terdapat pengaruh yang signifikan manajemen mutu terhadap kepuasan pasien. Berdasarkan hasil tersebut maka hipotesis penelitian yang menyatakan : "Diduga ada pengaruh positif manajemen mutu terhadap kepuasan pasien rawat inap di RSUD Kabupaten Karanganyar" dapat diterima. Dengan demikian, apabila manajemen mutu semakin baik maka kepuasan pasien rawat inap di RSUD Kabupaten Karanganyar juga akan meningkat.

b. Uji t pengaruh reliability terhadap kepuasan pasien

Hasil uji diperoleh nilai t hitung $(2,402)$ lebih besar dari t tabel $(1,960)$, maka Ho ditolak yang artinya terdapat pengaruh yang signifikan reliability terhadap kepuasan pasien. Berdasarkan hasil tersebut maka hipotesis penelitian yang menyatakan : "Diduga ada pengaruh positif reliability terhadap kepuasan pasien rawat inap di RSUD Kabupaten Karanganyar" dapat diterima. Hal itu berarti semakin baik faktor reliability maka kepuasan pasien juga akan meningkat.

c. Uji t pengaruh responsivenessterhadap kepuasan pasien

Hasil uji diperoleh nilai t hitung $(3,757)$ lebih besar dari t tabel $(1,960)$, maka Ho diterima yang artinya tidak terdapat pengaruh yang signifikan responsiveness terhadap kepuasan pasien. Berdasarkan hasil tersebut maka hipotesis penelitian yang menyatakan : "Diduga ada pengaruh positif responsiveness terhadap kepuasan pasien rawat inap di RSUD Kabupaten Karanganyar" dapat diterima atau ditolak. Hal itu berarti apabila responsiveness semakin baik maka akan meningkatkan kepuasan pasien. 
d. Uji t pengaruh empathyterhadap kepuasan pasien

Hasil uji diperoleh nilai t hitung $(2,955)$ lebih besar dari t tabel $(1,960)$, maka Ho ditolak yang artinya terdapat pengaruh yang signifikan empathy terhadap kepuasan pasien. Berdasarkan hasil tersebut maka hipotesis penelitian yang menyatakan : "Diduga ada pengaruh positif empathy terhadap kepuasan pasien rawat inap di RSUD Kabupaten Karanganyar" dapat diterima. Hal itu berarti semakin baik empathy maka kepuasan pasien juga akan meningkat.

\section{Uji Koefisien Determinasi (Adjusted $\mathbf{R}^{2}$ )}

Hasil uji determinasi menggunakan program SPSS diperoleh nilai adjusted $R$ square sebesar 0,929 atau 92,9\% yang berarti variabilitas variabel dependen yang dapat dijelaskan oleh variabilitas variabel independen sebesar $92,9 \%$ sedangkan sisanya $(7,1 \%)$ dijelaskan oleh variabel lainnya yang tidak dimasukkan dalam model regresi, antara lain biaya dan kompetensi petugas medis.

\section{KESIMPULAN}

Berdasarkan hasil pengujian yang telah dilakukan di atas maka dapat disimpulkan hal-hal sebagai berikut:

a. Terdapat pengaruh positif dan signifikan secara simultan manajemen mutu, reliability, responsiveness, dan empathy terhadap kepuasan pasien rawat inap di RSUD Kabupaten Karanganyar.

b. Terdapat pengaruh positif dan signifikan manajemen mutu terhadap kepuasan pasien rawat inap di RSUD Kabupaten Karanganyar.

c. Terdapat pengaruh positif dan signifikan reliability terhadap kepuasan pasien rawat inap di RSUD Kabupaten Karanganyar.

d. Terdapat pengaruh positif dan signifikan responsiveness terhadap kepuasan pasien rawat inap di RSUD Kabupaten Karanganyar.

e. Terdapat pengaruh positif dan signifikan empathy terhadap kepuasan pasien rawat inap di RSUD Kabupaten Karanganyar.

Berdasarkan kesimpulan hasil penelitian, dikemukakan saran-saran sebagai berikut :

a. Dalam Menunjang Manajemen Mutu Dapat Ditingkatkan Pengawasan Mutu Misalnya Membuat Suasana Nyaman Dengan Menambah Ruang Hijau Terbuka, Ikan Hias, Memberikan Buku Informasi, Tempat Duduk Yang Nyaman, Customer Service Yang Ramah.

b. Dalam Menunjang Kualitas Pelayanan Dari Dimensi Reliability maka Dapat Dilakukan Peningkatan Kualitas Melalui Prosedur Yang Mudah, Pelayanan Yang Sesuai, Cepat, Dan Adanya Kemudahan Dalam Memperoleh Akses Dan Informasi Pelayanan.

c. Dalam Menunjang Kualitas Pelayanan Dari Dimensi Responsiveness sudah Baik, Hanya Perlu Ditingkatkan Lagi Agar Lebih Senang Dengan Menanyakan Kebutuhan Pasien, Memberikan Penjelasan Yang Mudah, Adanya SOP Agar Dapat Memiliki Pedoman Dalam Pelayanan.

d. Dalam Menunjang Kualitas Pelayanan Dari Dimensi Empathy terdapat Beberapa Saran Yaitu Membuat Garis Senyum Yaitu Area Dimana Petugas Pemberi Layanan Diwajibkan Menyapa Dan Tersenyum Ramah Kepada Pasien. 
Eko Sutopo, dkk / Edunomika Vol.03, No. 01 (Februari 2019)

\section{DAFTAR PUSTAKA}

Alex S. Nitisemito. 2001. Marketing. Jakarta : Ghalia Indonesia.

Alfi Syahri Lubis dan Nur Rahmah Andayani. 2017. "Pengaruh Kualitas Pelayanan (Service Quality) terhadap Kepuasan Pelanggan PT. Sucofindo Batam. Journal of Business Administration Volume1, Nomor 2, September 2017, hlm.86-97.

Amin Wibowo. 2004..Service Quallity Information System: Kunci Sukses Pelayanan, Usahawan No. 10 Th. XXVII, Oktober, hal. 29-31.

Basu Swasta DH dan Irawan. 2002. Manajemen Pemasaran Modern. Yogyakarta: Liberty.

Basu Swasta, DH dan T. Hani Handoko. 2007. Manajemen Pemasaran Analisa Perilaku Konsumen. Yogyakarta : Liberty.

Basu Swasta, DH. 2007. Azas-azas Marketing. Yogyakarta : Liberty.

Dharmmesta, B.S. dan Handoko, H. 2007. Manajemen Pemasaran Analisa Perilaku Konsumen. Yogyakarta : Liberty.

Djarwanto, PS dan Pangestu Subagyo. 2003. Statistik Induktif. Yogyakarta : BPFE.

Engel, J.E., et. al. 2005.Perilaku Konsumen, edisi Bahasa Indonesia Jilid I. Jakarta : Binarupa Aksara.

Fandi Ciptono. 2005. Manajemen Pemasaran Jasa. Yogyakarta : Andi Offset.

Gerson, Richard F. 2002. Mengukur Kepuasan Pelanggan, Cetakan Kedua. Jakarta: PPM.

Heidjarhman Ranu Pandojo, Irawan dan Sukanto Reksohadiprodjo. 2001. Pengantar Ekonomi Perusahaan. Yogyakarta: Penerbit Fakultas Ekonomi UGM.

Irfan Islami. 2004. Manajemen Pelayanan dan Kepuasan Konsumen.Jakarta : LP3ES.

Istiqomah dan Sudarwati. 2015. “Analisis Kepuasan Publik Atas Kualitas Pelayanan di Satlantas Polres Sukoharjo”. GEMA Th. XXVII/49/Agustus 2014 - Januari 2015

Kotler, P dan Andreasen, A.R. 2005.Strategi Pemasaran untuk Organisasi Nirlaba. Yogyakarta : Gadjahmada University Press.

Kuswadi. 2004. Cara Mengukur Kepuasan Karyawan. Jakarta : Elex Media Komputindo Kelompok Gramedia.

Ma'ruf, M. H. (2016). Analisis Pengaruh Kualitas Pelayanan Terhadap Kepuasan Pasien Pada Rumah Sakit Umum Daerah Sukoharjo. Jurnal Akuntansi dan Pajak, 16(02).

Masri Singarimbun dan Sofyan Effendy. 2009. Metode Penelitian Survey. Jakarta : LP3ES. 
Eko Sutopo, dkk / Edunomika Vol.03, No. 01 (Februari 2019)

Mohd Afroz Pasha dan Razashah. 2018. "Impact of Service Quality on Customer Satisfaction : An Empirical Study in Selected Public and Private Sector Banks". International Refereed Research Journal Volume IX, Issue 1, January 2018.

Murti Sumarni dan John Soeprihanto. 2008. Manajemen Bisnis. Jakarta : LP3ES.

Parasuraman. 2000. Delivering Quality Service, Balancing Customer Perseption and Expectation. New York : The Free Press.

Philip Kotler. 2005. Manajemen Pemasaran : Analisa Perencanaan Implementasi dan Pengendalian. Jakarta : Erlangga.

Poerwodarminto, WJS. 2006. Kamus Umum Bahasa Indonesia.Jakarta : PN. Balai Pustaka.

Radiosunu, 2003. Manajemen Pemasaran. Yogyakarta : BPFE.

Rahadi Fitra Nova. 2010. "Pengaruh Kualitas Pelayanan Terhadap Kepuasan Pasien Rawat Inap Pada Rumah Sakit PKU Muhammadiyah Surakarta”. Skripsi. Dipublikasikan digilib.uns.ac.id. Surakarta : Universitas Sebelas Maret.

Ratminto dan Winarsih, Atik Septi. 2005. Manajemen Pelayanan. Yogyakarta: Pustaka Pelajar.

Sarwoto. 2003. Manajemen Pelayanan Publik. Jakarta : Ghalia Indonesia.

Siska Pratiwi. 2016. "Pengaruh Kualitas Pelayanan Terhadap Kepuasan Pasien Rawat Inap di Rumah Sakit Sultan Immanudin Pangkalan Bun Kalimantan Tengah". Jurnal Asosiasi Dosen Muhammadiyah Magister Administrasi Rumah Sakit Vol.2 No. 2 Juli 2016

Stanton, William J. 2006. Prinsip Pemasaran.Jakarta : Erlangga.

Suharso. 2009. Konsep-konsep Dasar Manajemen Pelayanan.Jogjakarta : Gadjah Mada University Press.

Winarno Surakhmad. 2002. Metode Penelitian Kualitatif. Bandung : Tarsito.

Yamit, Zulian. 2005. Manajemen Kualitas Produk dan Jasa. Yogyakarta: Ekonesia. 